\title{
EL MODELO DE ANÁLISIS ICONOLÓGICO: PROPUESTA APLICADA AL RELATO CINEMATOGRÁFICO
}

\author{
ICONOLOGICAL ANALYSIS MODEL: \\ APPLIED MOTION TO THE FILM STORY
}

\section{AUTORA}

\section{Clara Janneth Santos Martínez}

Doctora Comunicación Audiovisual y Publicidad II. Madrid, España. janneths@hotmail.com

\section{RESUMEN}

Se expone a continuación un modelo de análisis del relato cinematográfico, el cual se plantea desde el doble marco teórico de la Narrativa Audiovisual y el Análisis Iconológico. El modelo constituye una herramienta de soporte informativo basado en una estructura polidendrítica que facilita la desconstrucción del film de acuerdo con sus elementos cinematográficos, narratológicos y los componentes semióticos que explican la relación entre texto y contexto. Para ejemplificar dicha relación y explicar la trayectoria del modelo se ha seleccionado, dentro del cine español, la película "La Colmena" -obra cinematográfica de Mario Camus-, al considerar que en ésta hay elementos significantes que permiten interpretar el film como un síntoma de la cultura que representa y que además, habla de la sociedad española de postguerra.

\section{PALABRAS CLAVE}

Iconología - Narrativa Audiovisual - Cine - Relato - Cultura - Nuevas Tecnologías 


\section{ABSTRACT}

This article introduces an analytical model that acts as a tool to assist the analyst or student of cinema in the task of deconstructing the cinematographical récit (story), thereby facilitating the creation of an inventory and a linguistic description of the numerous themes that converge in a film. It is structured around a double theory framework: The ability of the audiovisual image to tell stories is taken from Jesús García Jímenez's Audiovisual Narrative, and I have also applied Erwin Panofsky's Iconological Analysis in order to explain and integrate the signifying elements in a cinematographical récit. These elements are understood as symptoms of something quite distinct, and are integrated in the Pre-Iconography, Iconography and Iconology triad.

I have relied on new computer technologies in the study of architecture and archaeology related to the cinematographical récit. In this way, I have created a dendrite relationship of audiovisual signifiers which have multiple sorting, quantifying and analytical combinatory possibilities. To do it, I have chosen an example by selected the Mario Camus' film "The Beehive".

\section{KEY WORDS}

Iconology - Audiovisual Narrative - Cine - Story - Culture -Technology

\section{ÍNDICE}

1. ¿Qué es el Modelo de Análisis Iconológico?

2. Marco teórico que lo sustenta

3. Fases del Modelo de Análisis Iconológico: Introducción de Datos; Ejecución del Modelo; Diagnóstico

4. Límites y consideraciones previas al uso del modelo

5. ¿A qué tipo de relatos cinematográficos se puede aplicar?

6. Bibliografía

7. Webgrafía 


\section{1. ¿Qué es el Modelo de Análisis Iconológico?}

El Modelo de Análisis Iconológico propone un modelo de análisis del relato cinematográfico. Todo análisis depende de unas pertinencias implícitas y/o explícitas, que señalan sus propios límites. En el caso del Modelo de Análisis Iconológico es pertinente proceder mediante la desconstrucción del texto fílmico para entender los significados.

El objeto de estudio -el relato cinematográfico-, tiene una naturaleza triádica que comprende, en primer lugar, las características relacionadas con la técnica cinematográfica; en segundo, aquello que tiene que ver con el filme como relato; y finalmente, es pertinente entender que la naturaleza fílmica asume e incluye el conjunto semiótico que interactúa en el film para crear la Semiosfera ${ }^{1}$ cultural que lo representa. Se habla aquí de una semiótica fílmica homologada del mundo real o de un mundo culturalmente posible.

El Modelo de Análisis Iconológico constituye una herramienta útil que se apoya en las Nuevas Tecnologías para proponer una interpretación del relato cinematográfico, partiendo de términos como Pre-Iconografía, en el que el modelo se sitúa en un nivel de inventario de significantes; Iconografía en el que el análisis continúa dentro de un nivel descriptivo; e Iconología, que define el análisis dentro de un nivel de interpretación. Así, el recorrido que realiza el analista inter-relaciona los 3 niveles de análisis iconológico, con 3 fases, a saber: Introducción de datos, Ejecución del análisis y Diagnóstico del film.

${ }^{1}$ LOTMAN, Yuri. La Semiosfera. Cátedra. Madrid. 1996. 


\section{Marco teórico}

El análisis se estructura bajo un doble marco teórico, partiendo de la Narrativa Audiovisual de Jesús García Jiménez ${ }^{2}$, por la que se intenta explicar la capacidad de la imagen audiovisual para contar historias; y, el Análisis Iconológico de Erwin Panofsky ${ }^{3}$, por el que se explican los elementos significantes del relato cinematográfico como síntomas de algo distinto. Así se realiza un trasvase y readaptación de significantes y significados, por lo que éste modelo revisa los elementos del Análisis Iconológico planteados por Panofsky en el análisis de la obra pictórica y los fusiona con los significantes audiovisuales que se encuentran en un film.

Al igual que Panofsky propone "restaurar los nexos que unen la obra de arte a su entorno"; en el relato cinematográfico se pueden detectar y restaurar los nexos que unen el mundo creado por el autor con un tipo de cultura que representa el relato fílmico, -bien sea la cultura de la representación o la cultura de lo representado-, lo cierto es que, el análisis se mueve en un terreno pragmático y opera como un modelo que articula texto y contexto para una interpretación de la obra fílmica.

El campo de acción del modelo es el análisis contextual, el cual tiene que ver con el modo en que el film traduce o elabora la realidad social ${ }^{4}$. Con ello se busca aportar inteligibilidad sobre el texto cinematográfico, y señalar que en esta medida, su naturaleza ecléctica apunta hacia una actualización analítica dentro de las Nuevas Tecnologías, sin olvidar herencias y legados de otros análisis como por ejemplo el realizado por Sigfried Kracauer $^{5}$ sobre la forma como las películas reflejan las

\footnotetext{
${ }^{2}$ GARCÍA JIMÉNEZ, Jesús. Narrativa Audiovisual. Cátedra. Madrid. 1993.

${ }^{3}$ PANOFSKY, Erwin. El significado en las artes visuales. Alianza Forma. Madrid. 1988.

${ }^{4}$ CASETTI Y DI CHIO, Francesco. Cómo analizar un film. Cátedra. Signo e Imagen. 1989. "... en el film actúa siempre un verdadero escenario social'. Pág. 266.

${ }^{5}$ KRACAUER, Sigfried. De Caligari a Hitler. Una Historia Psicológica del Cine Alemán. Paidós. Barcelona. 1985.
} 
tendencias que prevalecen en la mentalidad de Alemania en una época determinada, o las teorías sobre el análisis sintomático de David Bordwell6.

Este artículo presenta un Modelo de Análisis Iconológico que actúa como una herramienta que facilita al analista o estudioso del cine, el trabajo de desconstrucción considerando ésta una tarea larga y dispendiosa en lo que tiene que ver con el inventario y la descripción de la gran pluralidad y multiplicidad de significantes que alberga un film. El modelo valida, entonces, las Nuevas Tecnologías Informáticas para el estudio de la arquitectura y arqueología del relato cinematográfico. Ordena y cuantifica los significantes fílmicos brindando inteligibilidad semiométrica, pero además facilita y considera la acción interpretativa y/o cualitativa en la denominada fase de Diagnóstico, la cual compete directamente a la lógica y correcta asociación intelectual que efectúe el analista.

Dicha labor requiere criterio científico y una capacidad de síntesis interpretativa o "intuición sintética", que tal y como la definió Erwin Panofsky es una fuente de interpretación "condicionada por la psicología y la cosmovisión del intérprete" Finalmente, el modelo constituye un camino hacia la construcción de una verdadera sintomatología de la cultura o historia de los síntomas y/o símbolos que conforman la cultura.

\footnotetext{
${ }^{6}$ BORDWELL, David. El Significado del film. Paidós. Barcelona. 1995.

${ }^{7}$ PANOFSKY, Erwin. Pág. 57
} 


\section{Fases del Modelo de Análisis Iconológico: Introducción de datos, Ejecución del modelo, Diagnóstico}

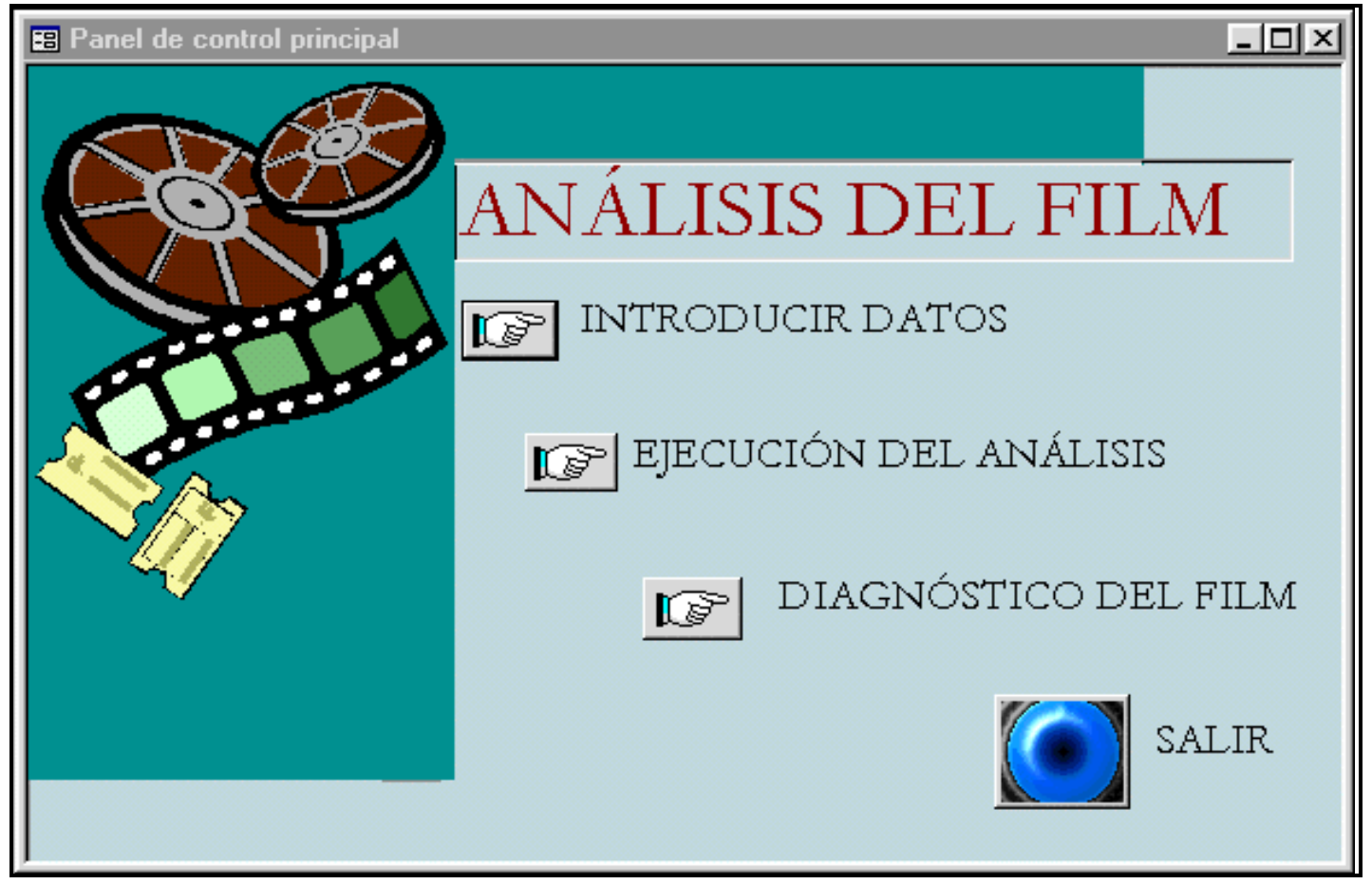

El modelo se diseña en una base de datos que almacena información organizada desde una triada que describe su recorrido: la fase de Introducción de Datos, la fase de Ejecución del Modelo y finalmente la fase de Diagnóstico. Antes de realizar la Introducción de Datos, se recomienda un primer contacto que pretende: realizar un pre-visionado del film o conjunto de films a analizar; conocer el material existente en torno al film; revisar las fuentes literarias que permiten reconstruir los nexos del film con el entorno de la obra, organizar un listado de hipótesis o conjeturas en torno a la dirección que puede tomar el análisis y, efectuar un primer esquema sobre los elementos que componen la historia.

En la Introducción de datos, el analista entra en contacto con el film desvertebrando sus partes cinematográficas, narratológicas y semiológicas. Para ello se siguen las pautas trazadas por cada una de las interfaces que presentan los elementos 
centrales del análisis. La introducción de datos comprende elementos como: Decorados o Espacios; Personajes; Secuencias con su respectiva descripción; Elementos de Imagen; Integración de las respectivas dendritas mediante el montaje interfácico y; Elementos semióticos pertinentes.

Fase 1: Introducir Datos

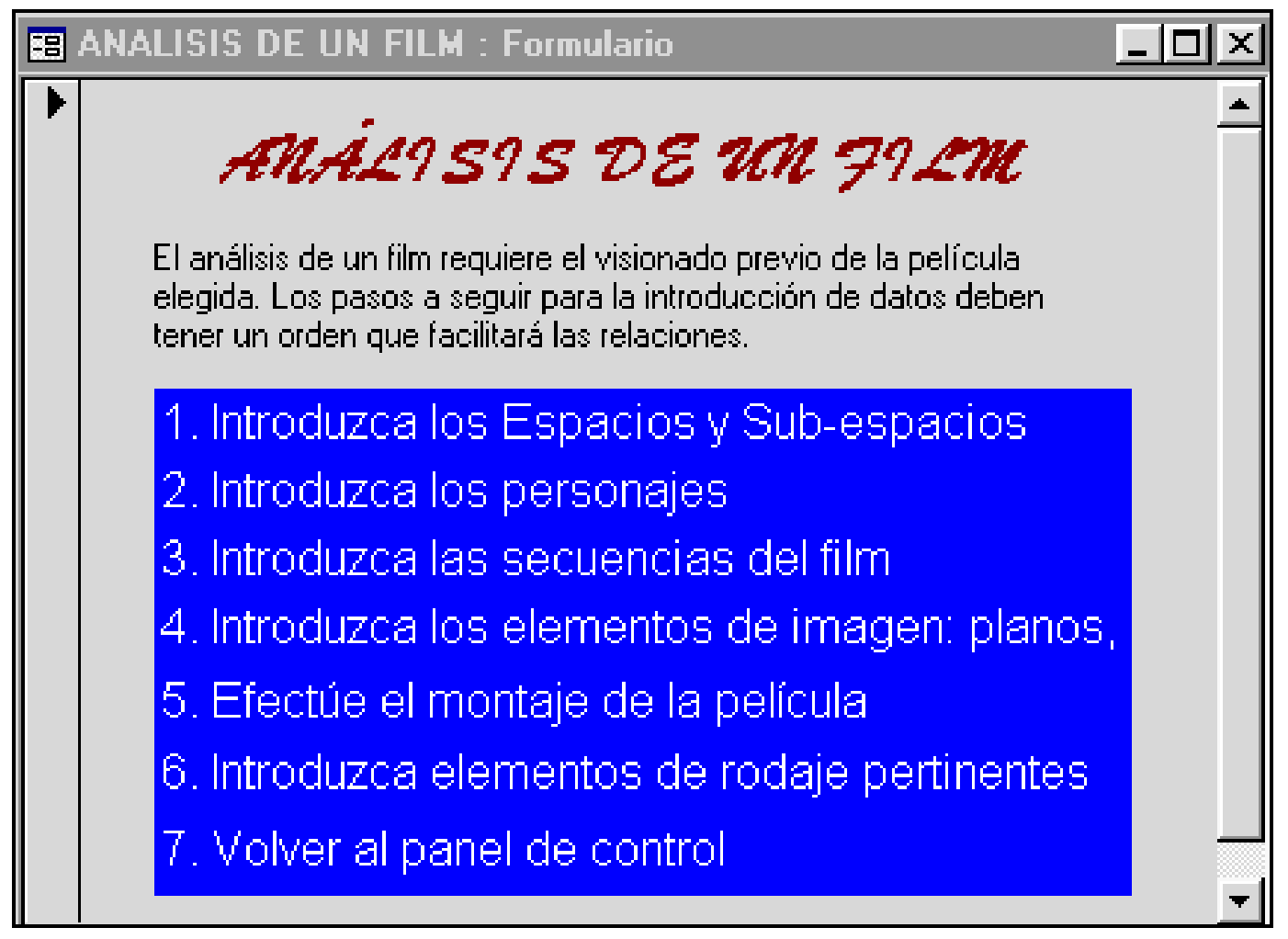

Los pasos que se proponen se presentan en una interfaz general y deben seguirse de manera lineal y ordenada. La introducción incluye los elementos propios del film con los que se efectuará un trazado a la manera de un diagrama cuya estructura se construye internamente gracias a la aplicación informática empleada y a las múltiples relaciones posibles.

Una vez introducidos los significantes del relato cinematográfico, el analista procede a observar, analizar y/o imprimir los datos que ofrece el modelo pudiendo acceder a 
la fase de Ejecución, la cual se subdivide en tres niveles: el pre-iconográfico, el iconográfico y el iconológico.

\section{Fase 2: Ejecución del Análisis}

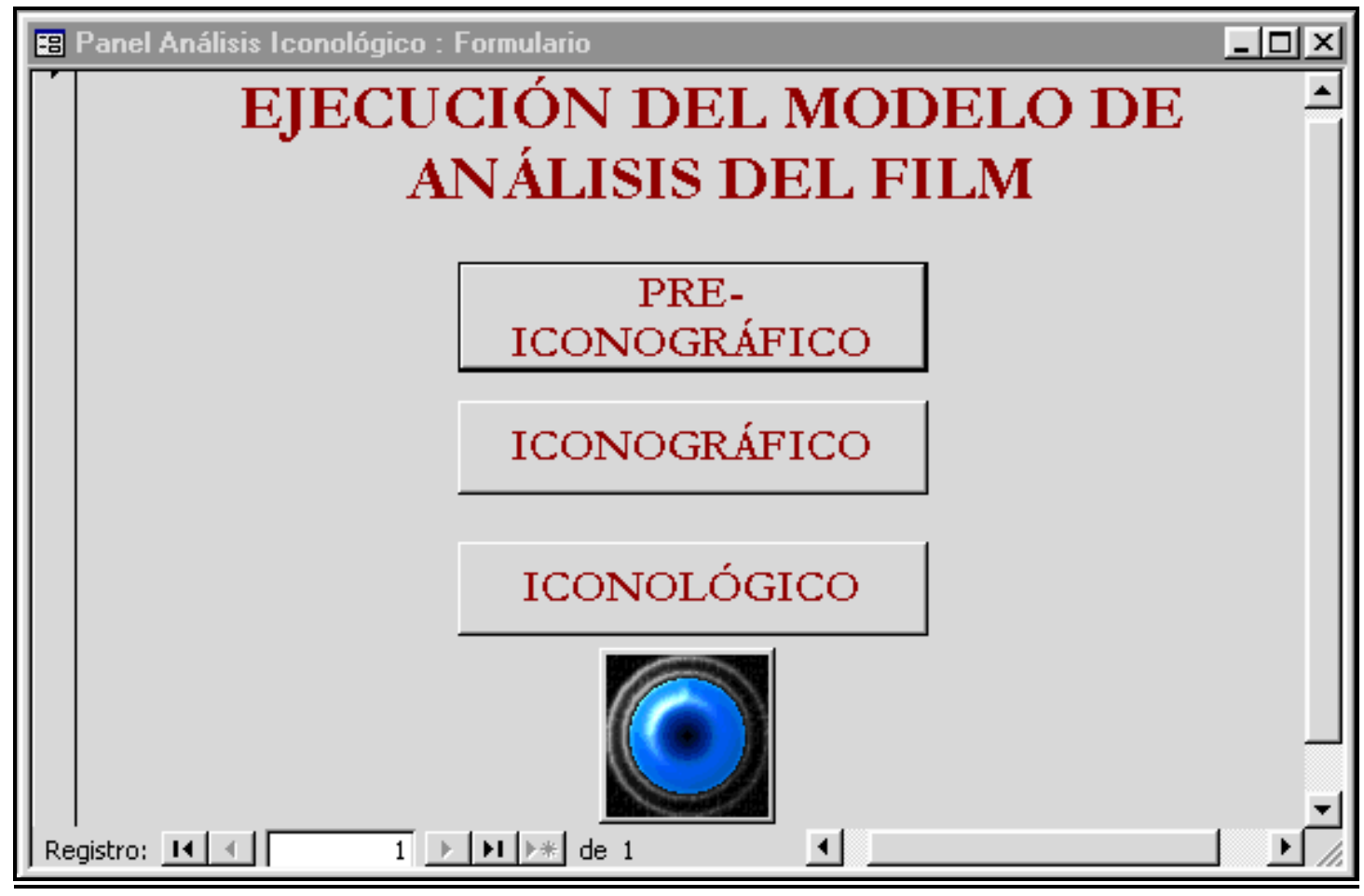

El Modelo de Análisis Iconológico, plantea que el Nivel Pre-Iconográfico se equipare con un inventario de los términos existentes en el film. En este nivel se producen dos derivaciones pertinentes: la primera es un inventario relacionado con los componentes propiamente cinematográficos en los que se ha re-estructurado el montaje fílmico y ante la que se tiene la opción de interactuar mediante consultas específicas. La segunda derivación, pretende construir el inventario que dará cuenta de la Semiosis fílmica, incluyendo elementos significantes relacionados con los espacios, los personajes, las acciones, el tiempo, el vestuario, la ambientación, los decorados y las historias narradas. 
- Nivel Pre-Iconográfico:

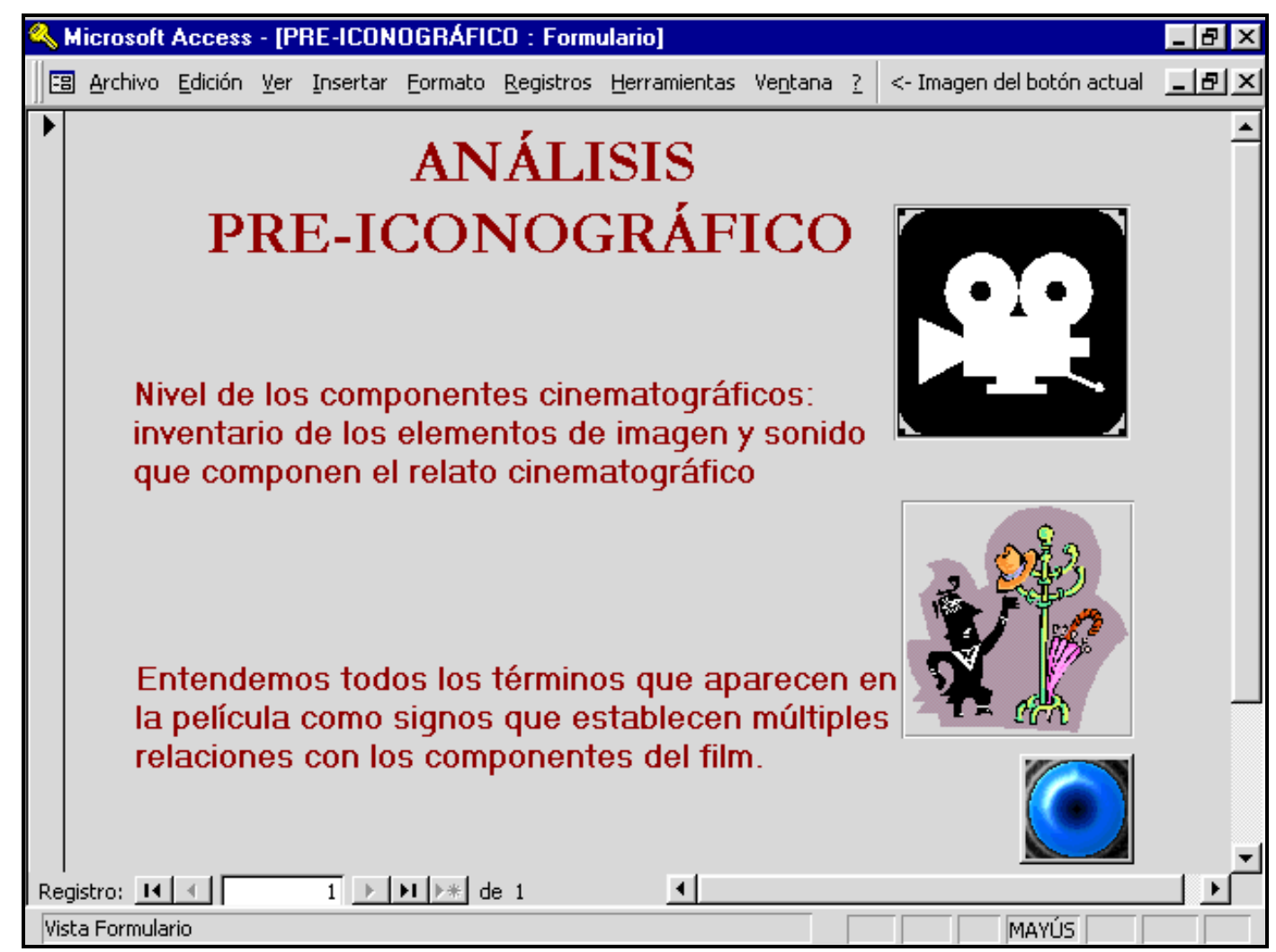

En segundo lugar, el análisis en el Nivel Iconográfico propone dividir y analizar el film desde el punto de vista del relato, es decir, asumiendo la dicotomía historia y discurso como estructura del análisis. De este modo es posible desvelar la forma como el director ha construido los componentes para conocer la estructura del film así como los elementos relevantes de la narración.

La historia, el 'qué' del discurso, responde a criterios cuantificables, como por ejemplo, número de personajes en un espacio dado, número de espacios y sus relaciones con otros espacios, número de acciones y personajes que interactúan en ellas, tiempo de cada acción, de cada personaje en un espacio, en todos los espacios, etc. La historia se convierte en el elemento donde la estructura dendrítica facilita el mayor número de datos con el apoyo de la estadística descriptiva. 
Este refuerzo marca, por una parte, la puesta en escena y por otra la escenografía o movimientos de los personajes de manera, que sus escenarios estén muy cuidados, sus decorados se monten en función de éstos y los espacios que crea desde el qué y el cómo marquen su postura personal como genio creador de los mismos, de manera que trascienda el espacio como código para llegar al ámbito, última escala de creación de lo que genéricamente hemos llamado espacio en el epígrafe ${ }^{8}$.

El discurso se convierte en un elemento que se organiza en un contínuum observado de acuerdo con la pertinencia significativa de los elementos dialogales, los elementos de significación en relación con un personaje y su vestuario, o la ambientación que le rodea, los decorados que habita, etc. Es decir, la continuidad que permite ver cómo se han construido los personajes o la continuidad que permite ver la relación entre las historias que se narran o la continuidad que nos muestra el narrador del film.

- Nivel Iconográfico:

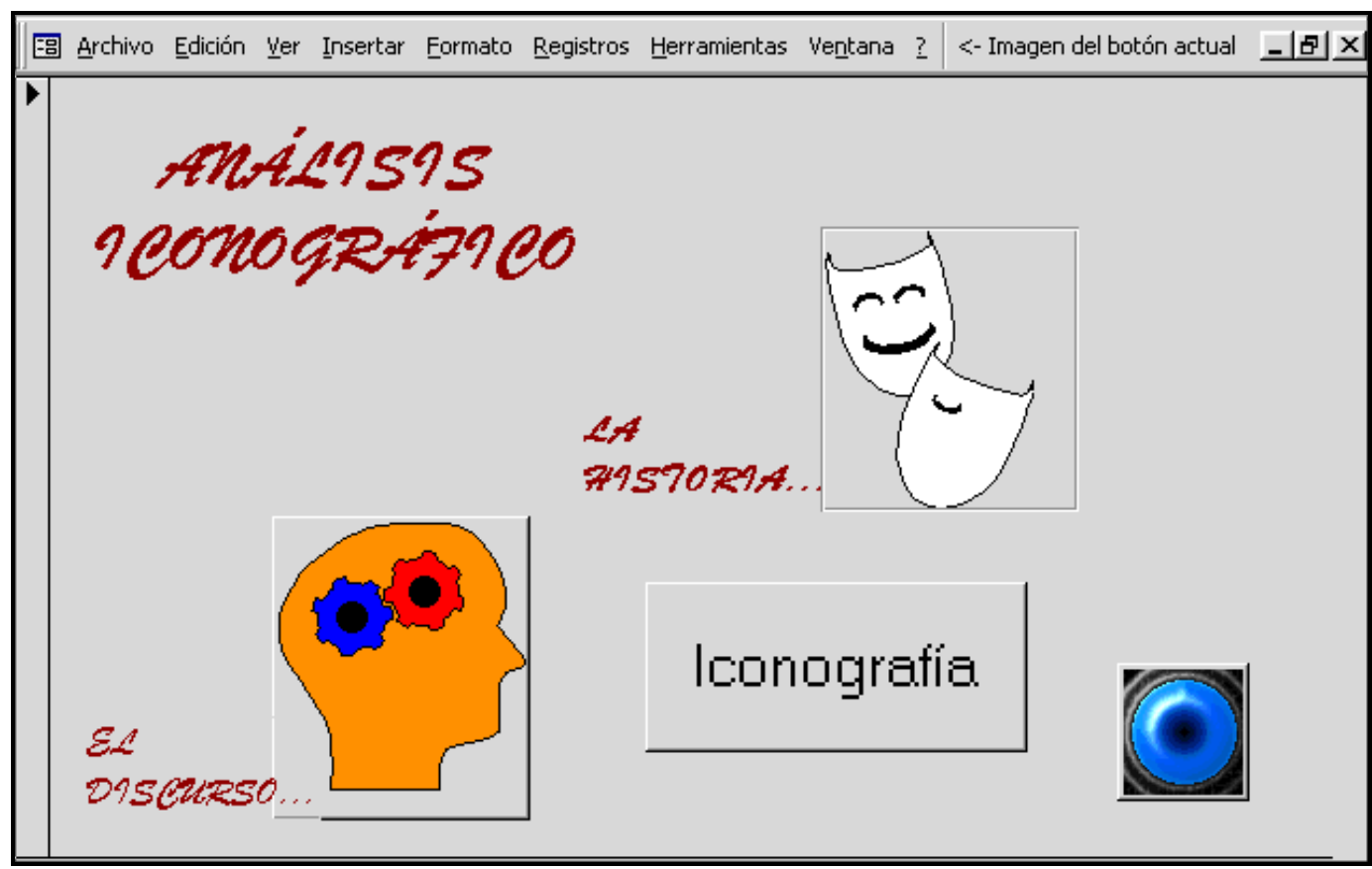

${ }^{8}$ CALDEVILLA DOMÍNGUEZ, David: El sello Spielberg. Madrid.1999. 
Finalmente, en el Nivel Iconológico, el analista realiza su interpretación tomando como base el conocimiento de las fuentes literarias existentes y su propia cosmovisión. La Iconología apunta a una interpretación en términos de cultura del texto cinematográfico, entendiendo que se construye una semiosfera que se define como un sistema semiótico compuesto de manifestaciones que se organizan según sean: simbolismos, pautas de comportamiento, usos de la vida social, el refranero popular extraído de esa cultura y los textos anidados que se relacionan con dicha cultura, y que se muestran mediante imágenes y sonidos en el film constituyendo el universo semiótico de la realidad fílmica construida por el autor.

- Nivel Iconológico:

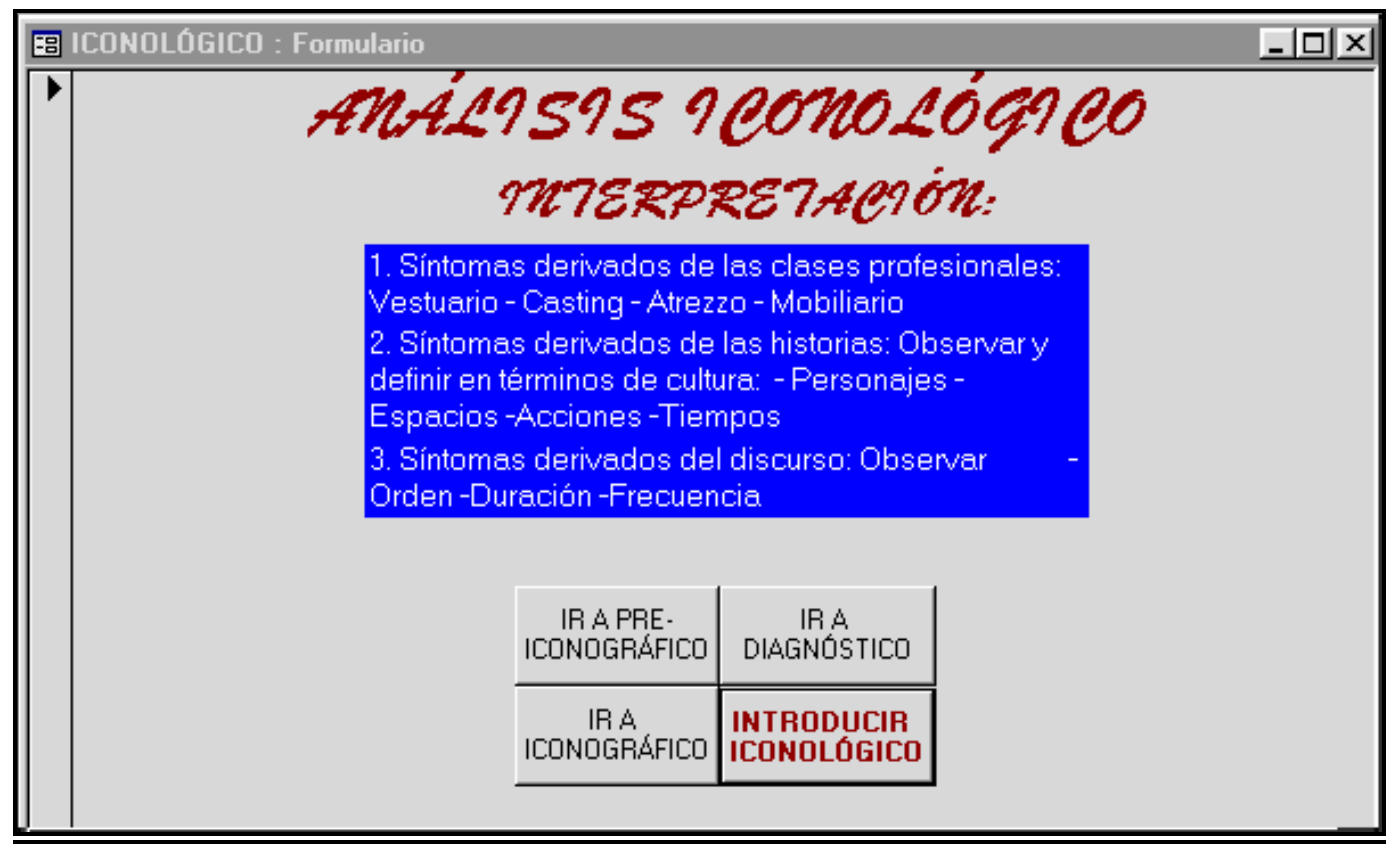

Conviene explicar brevemente el término cultura para una mejor comprensión del Nivel Iconológico. Se considera la cultura desde una doble óptica antropológica y semiológica. Desde la antropología conviene destacar el vínculo del hombre con la sociedad para una definición de la cultura; desde la semiología, y al hilo de las ideas de Lotman, la cultura se puede contemplar como una estructura que se encuentra dentro de una semiosfera en la que hay niveles, jerarquías y fronteras. La 
Semiosfera Cultural objetivo del analista asume que los significantes fílmicos se expresan de manera análoga a los términos de la realidad circundante.

En esta medida y teniendo en cuenta que el hombre se encuentra dentro de una semiosfera social que plantea su existencia semiótica, la Iconología en este modelo propone:

- Observar los elementos para el análisis del film en su contínuum.

- Considerar durante el análisis la relación de prioridad jerárquica que se concede al sujeto, en la que -afirmo con Lotman-, se expresa, reproduce, crea y actualiza la cultura como un organismo que se encuentra en constante transformación

- Definir la cultura como un sistema semiótico que, al hilo de la antropología social, incluye sistemas que comprenden los conocimientos, las creencias, los mitos y los ritos, las pautas de comportamiento, los valores, las actitudes, los simbolismos y convenciones que se dan en los hombres en cuanto que miembros vivos de una sociedad.

Con base en estos criterios, el Nivel Iconológico construirá o mejor, re-construirá dicha Semiosfera Cultural en cada film objeto de análisis para conocer y entender la cultura de lo representado.

Hasta aquí los niveles del modelo, dentro de la fase de Ejecución. El último paso del análisis tiene que ver con el llamado "Diagnóstico". Se trata del punto en que el analista realiza su visión totalizante, ha realizado el recorrido por las tres interfaces en las que ha definido y estudiado los elementos básicos relacionados con la técnica cinematográfica, los conceptos básicos relacionados con la narrativa audiovisual historia y discurso- $y$, finalmente ha compuesto la Semiosfera Cultural de acuerdo con sus observaciones. Aquí, el analista se orienta de acuerdo con su hipótesis inicial y cierra su análisis con una visión sintomática y totalizante del film o del conjunto del film. 
El nivel del Diagnóstico aporta un conocimiento reflexivo y sintomático al film. La obra cinematográfica en su conjunto -como señala Bordwell-, "se toma como un continente que el artista ha llenado de significados para que el observador los extraiga". El Diagnóstico elabora o construye una versión propia de la obra en términos de comprensión e interpretación sintomática del relato cinematográfico.

En el terreno técnico de manejo del modelo, las 3 interfaces del Diagnóstico integran una gran cantidad de datos acumulados y con posibilidades de impresión. El analista puede elegir en esta última fase y como un último paso cuáles opciones imprimir y de este modo toda su interpretación se juntará en un solo documento que brinda una visión del relato cinematográfico en términos de significados culturales.

\section{Fase 3: Diagnóstico}

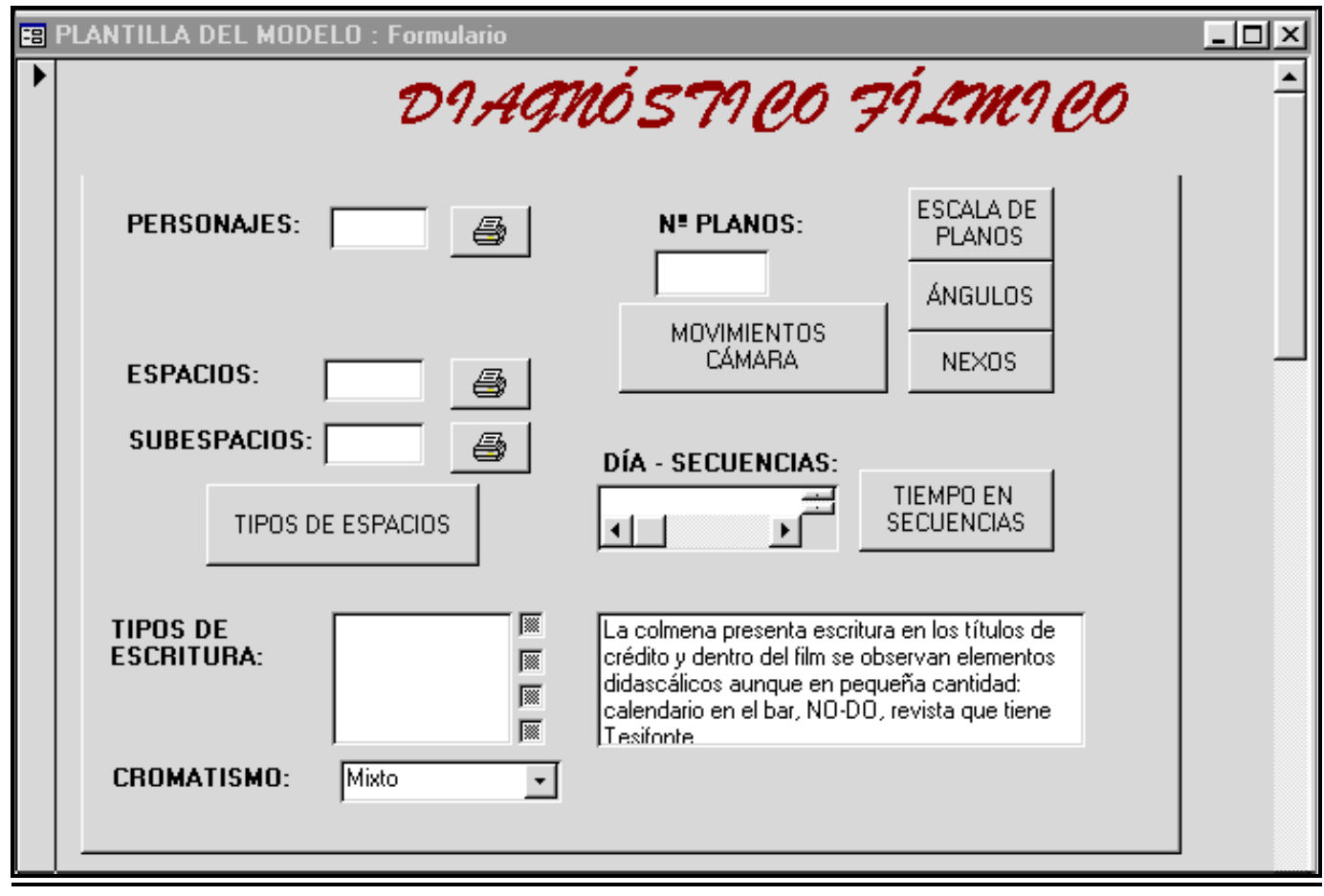


REVISTA DE LA SEECI.

Santos Martínez, Clara Janneth (1999): El modelo de análisis

iconológico: Propuesta aplicada al relato cinematográfico. No 3. Marzo.

Año III. Páginas: 80-100

ISSN: 1576-3420 DOI: http://dx.doi.org/10.15198/seeci.1999.3.80-100

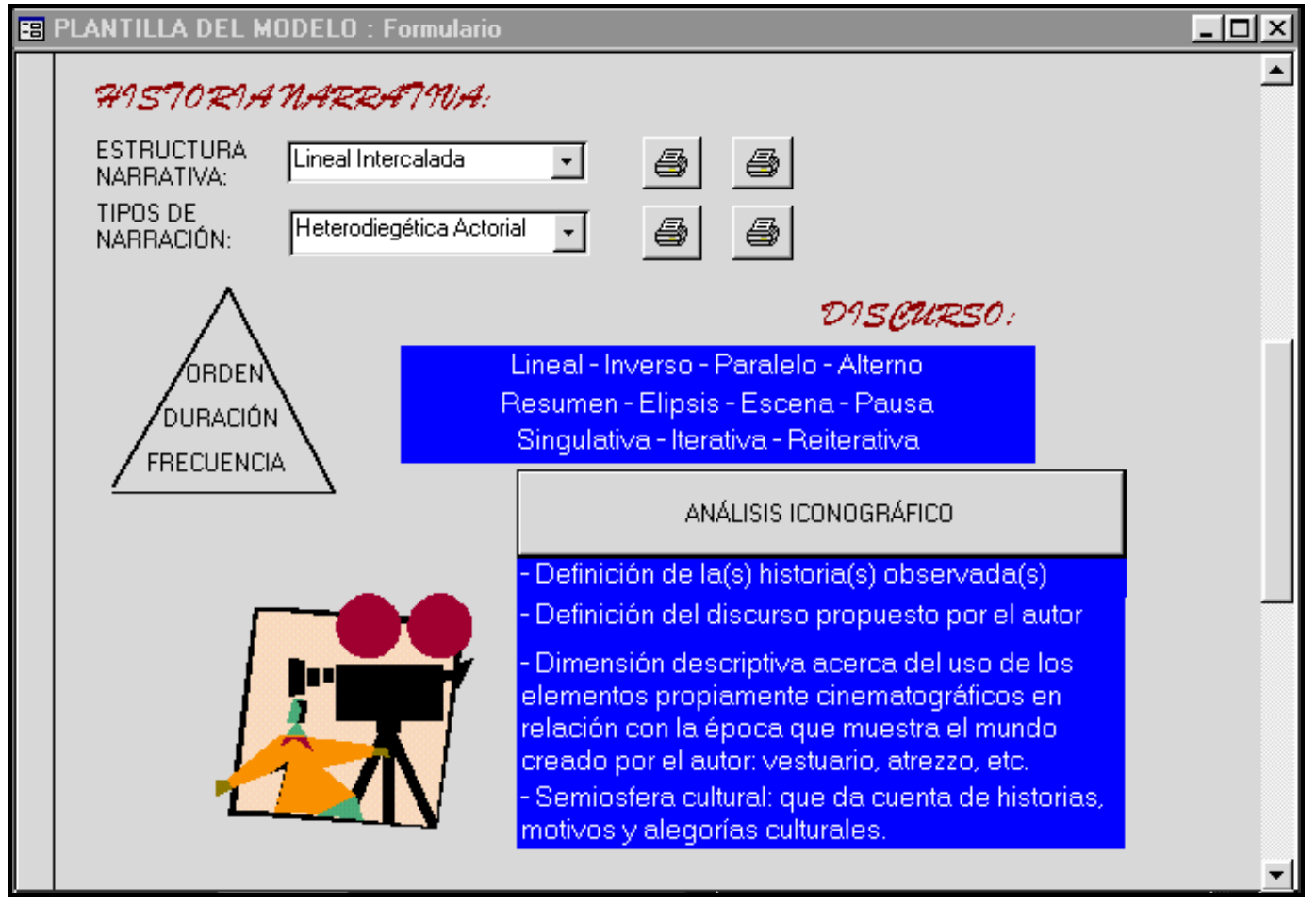

- Análisis final:

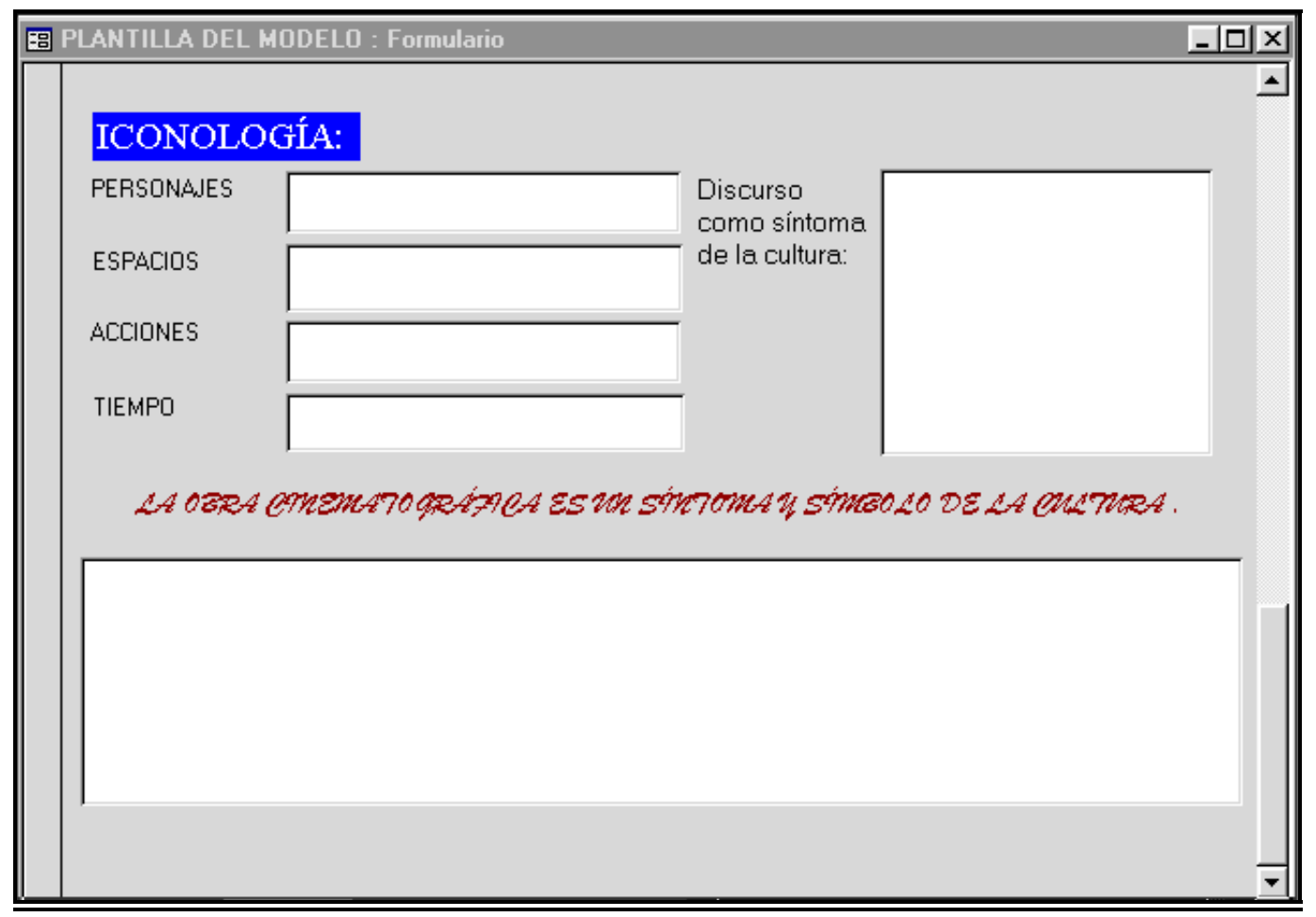




\section{Límites y Consideraciones Previas al uso del modelo}

Una vez planteado este marco que apunta a la génesis del modelo, su metodología, y trayectoria, conviene considerar algunos términos a la manera de convenciones teóricas, antes de explicar las Fases y los Niveles que operan en el mismo. Estos términos obedecen a convenciones y puntos de partida que -por razones de espacio, tan sólo señalaré brevemente sugiriendo ampliar toda información con la lectura de la tesis doctoral punto de partida del Modelo:

- La realidad histórica y psicológica, sociológica y/o cultural a la que remite el relato se considera como un referente semiológico, sólo en la medida en que dichos signos permitan comprobar que se manifiestan como síntomas en la película o películas objeto de estudio

- El director se considera el autor y único responsable del material fílmico, aún cuando la elaboración de la obra cinematográfica depende de todo un equipo de profesionales, los cuales, se han repartido el trabajo aportando un plus de significación a la totalidad fílmica

- La afirmación de Jacques Derrida: "el autor es un lugar en el que habla la cultura", nos acerca a entender y re-definir al director-autor del film. Considero que dicha afirmación propone una dimensión de autor como interlocutor, por tanto el autor cinematográfico se podría definir como

"el interlocutor que narra mediante imágenes visuales y auditivas y que, expresándose con signos y símbolos, condensa un mensaje -extraído de la cultura-, en una obra que representa historias mediante escenas que se proponen para ser leídas".

- El mundo creado por el director cinematográfico es un mundo análogo al real y además, los códigos que manejan autor y lector/espectador, se 
fundamentan en la lógica -implícitamente compartida y aprehendida-, del mundo real.

- Considerando que en el film existe una estructura semiótica se debe contemplar que esta tiene una jerarquía y unos límites. El film, se encuentra dentro de un sistema superior de significación en el que interactúan diversos sistemas semióticos y que a su vez se contienen dentro de la semiosfera de la cultura. Dicha semiosfera plantea lenguajes cerrados que conforman esferas definidas.

- Finalmente destacar la importancia que tiene para el análisis del film, la primacía o preponderancia de la figura del hombre -el sujeto como persona-, en la historia de los actos de representación y en la historia de la humanidad. Asumo, especialmente desde el cine, esa categorización egocéntrica del hombre como un elemento más de significado.

\section{Aplicación del Modelo de Análisis Iconológico:}

Este modelo puede aplicarse de manera total o parcial a prácticamente cualquier relato cinematográfico, sin embargo, se destaca la importancia y utilidad que representa para aquellas películas que se salen del modelo aristotélico. Aquellas películas cuya estructura dramática se quiebra y su desarrollo carga y acentúa uno o varios aspectos de la estructura narrativa para llenarla de significados. La funcionalidad que tendría el modelo en películas en las que predomina un enfoque hacia la estructura narrativa y, finalmente la utilidad correspondiente para los relatos cinematográficos que mantienen una estructura clásica.

Se ha realizado una ejemplificación del modelo con la película La colmena, obra adaptada por Mario Camus, basada en la novela de Camilo José Cela y que da muestra clara de cómo un film puede alejarse del modelo aristotélico. El primer 
elemento a observar en este film es la fragmentación del personaje. Camus reparte el protagonismo en la pluralidad de personajes entendiendo que se habla de la existencia de un personaje plural y no un personaje colectivo. Sus características no representan el alma ni el espíritu de la colmena ni de la sociedad española de aquella época. Simplemente, sus protagonistas son personajes con una pluralidad de características que los hacen partícipes de la cultura de los años 40 .

La colmena no narra una historia sino que es la historia de muchos sujetos que narran progresivamente su propia historia y que por lo general involucra a otros sujetos como una extensa red que se teje. De otro lado, el autor cinematográfico muestra desde la diégesis un manejo del tiempo centrado en una historia prácticamente- diurna, que ocurre durante la Semana Santa de 1943. El discurso de la cámara deja ver una estructura segmentada por días y que emplea 7 días con sus noches, para ser narrada. La estructura temporal plantea los términos de la sucesividad y la simultaneidad dentro de una cronología lineal. La historia transcurre simétricamente y discurre a diario mostrando que el tiempo lleva una marcha que el montaje intenta semejar con la realidad.

La estética empleada por Mario Camus a través de la cámara pretende semejarse a lo real. Tiene aspiraciones documentales y en sus soluciones estilísticas, predomina la transparencia de la cámara, para ello se apoya en técnicas que abogan por soluciones intermedias como puede ser el uso de planos medio y de busto, montaje mediante corte, utilización del plano/contraplano o iluminación justificada por la fuente, entre otras cosas. De los 899 planos rodados, 404 son planos de busto y dan cuenta de $35^{\prime}: 37^{\prime \prime}$ del film y 339 son planos medios, que narran $48^{\prime}: 18^{\prime \prime}$ del mismo.

La importancia de aplicar el Modelo de Análisis Iconológico, se percibe en el hecho de manejar con la herramienta informática 206 personajes que aparecen en imagen y 6 citados a través del audio. 899 planos y unos diálogos que vistos en un contínuum facilitaban encontrar diferentes aspectos del significado de los personajes 
e incluso del particular léxico que define la época. Cuestión que hubiera sido bastante difícil para cualquier analista sin contar con la ayuda del ordenador, o mejor de la aplicación informática que crea el modelo.

En La colmena de Camus se observa que existe una confluencia de elementos cotidianos que hablan del momento cronológico vivido. El film se desarrolla durante la Semana Santa de 1943 y recoge el sentido del Estado Nacional Católico que se promulga desde el franquismo. La directriz política estatal condujo a la sociedad española a olvidar la cruenta guerra civil que se vivió entre 1936 y 1939 y a empezar de nuevo. El mensaje que deja La colmena es el de una sociedad sumida en la cotidianidad que quiere seguir adelante y que a pesar del hambre, las inclemencias del tiempo o cualquier otra desazón cotidiana, la lucha por subsistir diariamente continúa, a pesar del pesimismo y las situaciones que se repiten día a día sin mostrar mayores modificaciones.

En el caso de películas cuya estructura dramática se observa con claridad, tal vez la validez del modelo se justificaría por la ordenación metodológica y las pautas para el análisis en términos de cultura. No obstante, un análisis minucioso acerca de los personajes o el espacio o las acciones, tal vez no tendría tanta validez, salvo en el conjunto de la obra de un autor. Podríamos explicar realmente la recurrencia de elementos de estilo o de elementos narrativos en el cine de un autor determinado y allí tendría plena aceptabilidad el uso de la herramienta informática. 


\section{Bibliografía}

BAL, MIEKE. Teoría de la Narrativa. Cátedra. Madrid. 1987.

BARTHES, ROLAND. Elementos de Semiología. Comunicación. Madrid. 1971.

BOLÍVAR, ANTONIO. El Estructuralismo: de Lévi-Strauss a Derrida. Cincel. Madrid. 1985.

BURCH, Noel. El Tragaluz del Infinito. Cátedra. Madrid. 1991.

BURCH, Noel. Praxis del Cine. Fundamentos. Madrid. 1983.

CALDEVILLA DOMÍNGUEZ, David. El sello Spielberg. Tesis doctoral. Madrid. 1999.

CASETTI, Francesco. El Film y su Espectador. Cátedra. Signo e Imagen. Madrid. 1989.

CASETTI Y DI CHIO, Francesco. Cómo Analizar un Film. Paidós. Barcelona. 1991.

CHATMAN, Seymour. Historia y Discurso: La estructura narrativa en la novela y el cine. Taurus. Madrid. 1990.

CHION, Michel. Cómo se Escribe un Guión. Cátedra. Signo e Imagen. 1990.

CHION, Michel. El Cine y sus Oficios. Cátedra. Signo e Imagen. Madrid. 1992.

CHOMSKY, Noam. El Lenguaje y el Entendimiento. Planeta. Barcelona. 1992.

ECO, Umberto. Cómo se Hace una Tesis: Técnicas y Procedimientos de Estudio, Investigación y Escritura. Círculo de Lectores. Barcelona. 1989.

FUNDESCO. Multimedia: Tendencias. Fundesco. Madrid. 1996.

GARCÍA JIMÉNEZ, Jesús. El Nacimiento de una Nueva Narratividad. Rev. Telos. Madrid. 1993. 
GARCÍA JIMÉNEZ, Jesús. La Imagen Narrativa. Paraninfo. Madrid. 1995.

GARCÍA JIMÉNEZ, Jesús. Narrativa Audiovisual. Cátedra. Madrid. 1993.

GARCÍA JIMÉNEZ, Jesús. Radiotelevisión y Política Cultural en el Franquismo. CSIC. Madrid. 1980.

JAKOBSON, Román. Lingüística y Poética. Cátedra. Madrid. 1988.

KRACAUER, Sigfried. De Caligari a Hitler. Historia psicológica del cine alemán. Paidós. Barcelona. 1985.

LOTMAN, Yuri. Estética y Semiótica del Cine. Col. Punto y Línea. Barcelona. 1979.

LOTMAN, Yuri. La Semiosfera. Cátedra. Madrid. 1996.

MITRY, Jean. Estética y Psicología del Cine. Las Formas. Siglo XXI. 1989.

MITRY, Jean. Estética y Psicología del Cine. Las Estructuras. Siglo XXI. 1998.

MORENO, Isidro. La Convergencia Interactiva de Medios: Hacia la narración hipermedia. UCM. Madrid. 1998.

MOST, Jacob. Manual Práctico para Iniciarse como Director de Cine. Ed. CIMS. 1998.

NEGROPONTE, Nicolás. El Mundo Digital. Ediciones B. Barcelona. 1995.

ONAINDÍA, Mario. El Lenguaje Fílmico en la Época Clásica: Billy Wilder". Vitoria. 1992.

PANOFSKY, Erwin. El Significado en las Artes Visuales. Alianza Forma. 1979.

PANOFSKY, Erwin. Estudios sobre Iconología. Alianza Universidad. 1972.

PANOFSKY, Erwin. La Perspectiva como Forma Simbólica. Tusquets. 1995.

PROPP, Vladimir. Las Raíces Históricas del Cuento. Fundamentos Madrid.1987

PROPP, Vladimir. Morfología del Cuento. Akal. Madrid. 1985. 
SANTOS, Clara Janneth. Aplicación de un Modelo de Análisis Iconológico a la Cultura de Posguerra en el Cine Español: El caso de La Colmena". Tesis Doctoral Universidad Complutense de Madrid. Madrid. 1999.

SANTOS, Clara Janneth. Entrevista a Amando de Miguel. Madrid. 1999.

SANTOS, Clara Janneth. Entrevista a Mario Camus. Madrid. 1995.

VELILLA, Ricardo. Saussure y Chomsky: Introducción a su Lingüística. Cincel. Madrid. 1987.

\section{Webgrafía}

AA.VV. La Decadencia Universal del Siglo XX. Power CD-Rom. ABC. 1998.

AA.VV. Historia de España en CD-Rom. 1998.

DRAMÁTICA. www.dramatica.com

MASSACHUSSETTS INSTITUTE TECHNOLOGY. www.media.mit.edu

THE MAGIC OF CREATIVE WRITING. www.skillroad.com

SOFTWARE DE PRODUCCIÓN Y DESGLOSE CINEMATOGRÁFICO.

www.screenplay.com/index.html

SOFTWARE SCREENWRITING. www.ashleywilde.com

STORY BUILDERS SOFTWARE. www.sVsoft.com 